Title: Exploring knowledge, attitudes and experience of genitourinary symptoms in women with early breast cancer on adjuvant endocrine therapy

\title{
Authors:
}

Dr Mariana S. Sousa $(\mathrm{MD}, \mathrm{PhD})^{1,2}$

Dr Michelle Peate (BSc, GradDipSc, MScMed, PhD) $)^{3,4}$

A/Prof. Craig Lewis (MBBS, MMed, FRACP) $)^{1,5}$

Ms Sherin Jarvis (BAppSc (Physio) $)^{6}$

Ms Amanda Willis (BMedSc, MScMed(RH\&HG), MGC, PhD candidate) $)^{1,5}$

Prof. Martha Hickey (MBChB, FRANZCOG, MD, PhD) $)^{3,4 *}$

Prof. Michael Friedlander (AM, MBChB(Hon), MRCP, FRACP, PhD) $)^{1,5} *$

* Joint senior authors

Affiliations: ${ }^{1}$ Prince of Wales Clinical School, University of New South Wales, Sydney, Australia; ${ }^{2}$ School of Nursing and Midwifery, Western Sydney University, Centre for Applied Nursing Research, South Western Sydney Local Health District, Ingham Institute for Applied Medical Research, New South Wales, Australia; ${ }^{3}$ Department of Obstetrics and Gynaecology, University of Melbourne, Victoria, Australia; ${ }^{4}$ The Royal Women's Hospital, Victoria, Australia; ${ }^{5}$ Department of Medical Oncology, Prince of Wales Hospital, New South Wales, Australia; ${ }^{6}$ Pelvic Floor Physiotherapy, Women's Health \& Research Institute of Australia, New South Wales, Australia.

Corresponding author: Dr Mariana S. Sousa, Locked Bag 7103, Liverpool BC, NSW 1871, Australia. T: +61 (2) 87389376 F: +61 (2) 87389206 E: m.sousa@westernsydney.edu.au

Authors' email addresses: m.sousa@westernsydney.edu.au;

michelle.peate@unimelb.edu.au; craig.lewis@sesiahs.health.nsw.gov.au; sherin.jarvis@gmail.com; amanda.willis@student.unsw.edu.au; hickeym@unimelb.edu.au; michael.friedlander@unsw.edu.au

\section{Funding source}

This is the author manuscript accepted for publication and has undergone full peer review but has not been through the copyediting, typesetting, pagination and proofreading process, which may lead to differences between this version and the Version of Record. Please cite this article as doi: $10.1111 /$ ecc. 12820

This article is protected by copyright. All rights reserved 
No financial support was received to develop this study.

\section{Competing interest}

The authors confirm that there is no conflict of interest between themselves and others that might bias their work.

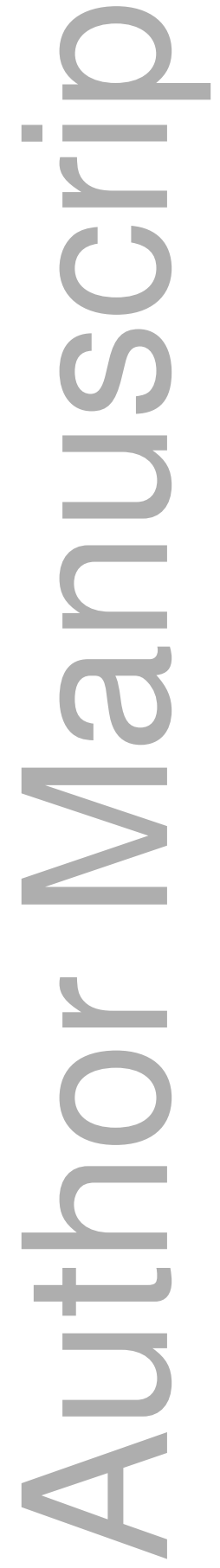


DR. MARIANA S. SOUSA (Orcid ID : 0000-0001-5034-9946)

Article type : Original Article

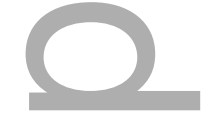

西

ABSTRACT

Clinical trials of adjuvant endocrine therapy in women with early breast cancer have consistently reported that genitourinary symptoms are common. However, little is known about women's experiences of genitourinary symptoms, their views about the symptoms and how they impact on their lives. The aim of this study was to explore knowledge, attitudes and experiences of genitourinary symptoms among women receiving adjuvant endocrine therapy for early breast cancer. Thirty-two semi-structured interviews were conducted and subjected to a rigorous qualitative analysis.

Genitourinary symptoms were commonly reported to negatively impact on personal, social and physical activities, were often attributed to anxiety and stress and were a source of embarrassment. Women also commented on the limited information available or provided regarding the potential genitourinary adverse effects of adjuvant endocrine therapy. There was a general lack of awareness that their symptoms could be associated with or exacerbated by adjuvant endocrine therapy. Women indicated a preference to receive information and advice about potential management options from either their general practitioner or specialist. These findings underscore the importance of improving communication and increasing awareness among both clinicians and patients about the potential impact of adjuvant endocrine therapy on genitourinary symptoms.

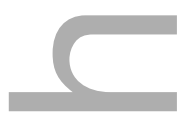

Key words: Breast cancer, Genitourinary symptoms, Endocrine therapy, Information needs, Patientreported experience, Qualitative study

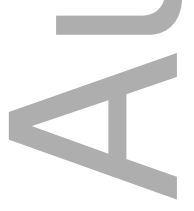




\section{INTRODUCTION}

Breast cancer remains one of the leading causes of cancer-related death among women, but mortality rates have continuously declined over the last three decades (Australian Institute of Health and Welfare, 2014). Most breast cancers are oestrogen-dependent and wide use of adjuvant endocrine therapy has contributed to the sustained decline in breast cancer mortality rates (Schiavon and Smith, 2014; Sheri and Dowsett, 2012). Adjuvant endocrine therapy is also associated with many adverse effects that can significantly affect quality of life (QoL) and may lead to early discontinuation of treatment and poor compliance, which could compromise overall survival (Partridge et al, 2008; Murphy et al, 2012). Consequently, improved understanding of endocrine treatment side effects and improved management of the adverse effects is of fundamental importance and remains a challenge.

Genitourinary symptoms affect around 50 to $75 \%$ of women taking adjuvant endocrine therapy for breast cancer (Trinkaus et al, 2008; Baumgart et al, 2011; Chin et al, 2009; Lester et al, 2012). Symptoms may include (but are not limited to) vaginal dryness, vaginal soreness, urinary urgency, burning and incontinence and are likely due to the anti-oestrogenic effect of adjuvant endocrine therapy (Chin et al, 2009; Lester et al, 2012; Donovan et al, 2012). Research on the impact of genitourinary symptoms in women with breast cancer is relatively scarce and most work has typically focused on quantitative outcomes such as frequency and grade of symptoms. Importantly, there have been no qualitative studies exploring the experiences of women taking adjuvant endocrine therapy with respect to genitourinary symptoms, their views about the symptoms and how they impact on their lives. Genitourinary symptoms can negatively affect multiple domains of QoL including sexual functioning (Baumgart et al, 2013; Lester and Bernhard, 2009; Zibecchi et al, 2003; Gupta et al, 2006; Sousa et al, 2017). Understanding the impact of the genitourinary adverse effects of adjuvant endocrine therapy in women with early breast cancer is a recognised gap in the published literature (Niravath et al, 2014). Most women with early breast cancer are postmenopausal and it is well known that pre-existing genitourinary symptoms are also common in this population (Portman and Gass, 2014). Adjuvant endocrine therapy may exacerbate these symptoms, but by how much or how often this happens is not well documented.

This qualitative study aimed to explore knowledge, attitudes and experiences of genitourinary symptoms in women receiving endocrine therapy. We sought to understand the impact of genitourinary symptoms on daily life, sexual activity and healthcare-seeking behaviour. The study also explored whether the information needs of these women with respect to genitourinary concerns, including available management options, were being met. Women's preferences regarding provision of information, including type, source and timing, were also explored. We envisaged that this study would provide greater insight into the significance and impact of these symptoms for women and 
promote more research into safe and effective management strategies, which could potentially improve QoL and sexual function in this large and growing population of women taking long-term adjuvant endocrine therapy.

\section{METHOD}

\section{Sampling and recruitment procedure}

Eligible participants were identified from the patient database of the Department of Medical Oncology of two metropolitan hospitals in Sydney, Australia. One is a public teaching large tertiary referral hospital that receives patients from all over the state of New South Wales and the other is a private tertiary hospital. The following inclusion criteria were used: female, diagnosed with early stage breast cancer (stages IA, IB, IIA and IIB) (American Joint Committee on Cancer, 2010), aged over 18 years, competent in English, and receiving adjuvant endocrine therapy (either tamoxifen - TAM, or an aromatase inhibitor - AI). Women were excluded if they had a history of genitourinary cancer and were unable to give informed consent.

Women with at least one genitourinary symptom who had received either an AI (Group A - GA) or TAM (Group T - GT) were purposively sampled to ensure the range of experiences of women taking adjuvant endocrine therapy were represented, based on the differences in prescribing and symptomatology between the two drugs reported in the literature (Thurlimann et al, 2005; Howell et al, 2005; Buzdar et al, 2006; Fallowfield et al, 2006; Morales et al, 2004; Cella et al, 2006). Sampling ceased when informational redundancy was reached in both groups (Marshall, 1996; Morse, 1995), that is no new information or themes were emerging from the data.

Women were sent an introductory letter from their treating medical oncologists outlining the nature of the study and inviting them to participate. A detailed participant information pamphlet, response sheet, consent form and a reply paid envelope were enclosed. Women who expressed an interest by returning the response sheet or leaving a message on a free-of-charge telephone number, received a telephone call from the researcher (MSS) who provided further information about the study, obtained consent via reply paid postage and arranged a time for the interview.

\section{Data collection}

Given the sensitivity of the topic, and so as not to exclude women who were unable to travel to the interview sites, participants were offered the option of either face-to-face or telephone interviews. 
Face-to-face interviews were conducted in a private interview room at the treating hospital or nearby University. All interviews were conducted by MSS, a female gynaecologist with substantial clinical and research experience in breast cancer care. The interviews were audio-recorded and transcribed verbatim.

Interviews followed a topic guide developed after a review of the relevant literature and expert discussion; experts included an oncologist, urologist, psychologist, pelvic floor physiotherapist, consumer, and two gynaecologists. The topic guide included questions that explored women's reporting and experiences of genitourinary symptoms, the perceived impact of symptoms on daily life and sexual function, treatment expectations and help-seeking behaviour, including motivators and barriers to seeking healthcare. The interviews also explored women's preferences regarding type, source and timing of provision of information and interventions related to genitourinary symptoms. A screening question was included at the beginning of the interview guide: 'Do you have any genitourinary symptoms? (Prompt: such as burning, incontinence, urgency, or others)'. If participants answered 'no' to the screening question, only sociodemographic and clinical information were collected in the interview and participants were thanked for their time. If participants reported any type of genitourinary symptom, the interviewer proceeded with the rest of the interview. Interviews lasted an average of about 25 minutes.

\section{Data analysis}

The coding and identification of themes were informed by the conceptual qualitative framework of Miles and Huberman (2002). Transcripts were checked concurrently with data collection, and emerging themes were discussed to establish additional lines of enquiry in subsequent interviews to ensure that all themes were fully explored. The final number of interviews was determined by the point at which data saturation was reached. Thematic analysis was a recursive process that entailed becoming familiar with the data, continuous coding, the development and refinement of themes reflective of the issues introduced by participants and uncovered during exploration of the data. Themes and coding categories were integrated into a preliminary coding tree developed through independent coding of a random sample of four transcripts (two from each group) by two research team members (MSS and MP) and an audit log was maintained to record the development of a preliminary coding tree. Themes were identified deductively in accordance with the aims and inductively by the data. Coding discrepancies were resolved through discussion and the coding tree was refined before each transcript was fully coded line-by-line by MSS using a qualitative analysis software package (NVivo 10, QRS International 2012). The structural analysis led to four main themes and twelve subthemes illustrating women's experiences with symptoms. The first theme, 
understanding the experiences of genitourinary symptoms, describes how the participants report symptoms, identify their cause and show their attitudes towards symptoms, their perceptions of the impact of symptoms on their daily life and on sexual function. The second theme, help-seeking behaviour, reveals participants' motivations and obstacles to seeking help as well as their helpseeking behaviour specific to sexual concerns. The third theme, treatment received and appraisal, discusses how, what and if women had access to treatment including their expectations about treatment outcomes. Finally, the fourth theme, information needs and preferences, exposes the participants' unmet needs, their preferred source and amount of information and preferred timing of its delivery. Descriptive statistics were used to explore quantitative data (sociodemographic and clinical characteristics) using IBM SPSS 21.0 (IBM Corp., Armonk, NY).

Throughout this manuscript, quotations are denoted according to the type of endocrine therapy undertaken by participants (i.e. their group: $\mathrm{GA}=\mathrm{AI} ; \mathrm{GT}=\mathrm{TAM}$ ) and menopausal status at diagnosis $($ Pre $=$ premenopausal; Post $=$ postmenopausal $)$, followed by their unique identifier.

\section{Ethics}

Ethical approval for this study was granted by the South Eastern Sydney Local Health District Human Research Ethics Committee.

\section{RESULTS}

\section{Sample}

A total of 67 letters of invitation were sent (Fig. 1). Twenty-two women did not respond. Of the 45 responders, 11 declined participation, one could not be contacted for interview, one was ineligible to participate (due to discontinuation of adjuvant endocrine therapy), and 32 opted for either a telephone $(n=23)$ or face-to-face $(n=9)$ interview. Of the 32 women interviewed, $13(41 \%)$ reported no genitourinary concerns (five on TAM and eight on AI), and only sociodemographic and clinical information were collected in the interview. The other 19 women (59\%) who fulfilled the study criteria and reported experiencing at least one genitourinary symptom completed the rest of the interview $(\mathrm{GA}=11$ and $\mathrm{GT}=8)$. The sociodemographic and clinical characteristics of all women are shown by group in Table 1. The average age of GA was 66 years (range 56-77), and that of GT was 52 years (range 42-67). Nearly half (47\%) of these women were married or partnered, and the average time in that relationship was 34 years. The majority of women (68\%) were postmenopausal at the time of diagnosis and the average time since menopause was 11 years. Almost $70 \%$ had children (average 
two vaginal births). The average time since diagnosis of breast cancer was three years and participants had been using endocrine treatment for an average of 26 months.

[Insert Fig. 1 here]

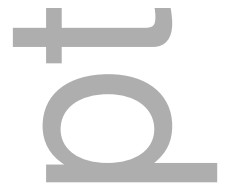

[Insert Table 1 here]

\section{Understanding the experiences of genitourinary symptoms}

In the interviews, women were encouraged to talk about their experience of, and attitudes towards genitourinary symptoms. Participants acknowledged and described their genitourinary problems, their beliefs about their causes, the impact of symptoms on their daily routine, relationships and sexual function, and any action taken to help manage symptoms.

Reporting of genitourinary symptoms

Across GA and GT, involuntary leakage $(\mathrm{GA}=8, \mathrm{GT}=6)$ and urgency $(\mathrm{GA}=7, \mathrm{GT}=6)$ were the most frequently mentioned symptoms. Other symptoms reported included urinary frequency $(\mathrm{GA}=2$, $\mathrm{GT}=5)$, nocturia $(\mathrm{GA}=5, \mathrm{GT}=2)$, recurrent urinary tract infection (UTI) $(\mathrm{GA}=2, \mathrm{GT}=2)$, genital prolapse $(\mathrm{GA}=3, \mathrm{GT}=1)$, burning $(\mathrm{GA}=1, \mathrm{GT}=2)$, discomfort/soreness $(\mathrm{GT}=2)$, overactive bladder $(\mathrm{GT}=1)$ and dyspareunia $(\mathrm{GA}=1)$. Table 2 provides a summary of the reported genitourinary problems with quotations as exemplars of how women described their experiences.

[Insert Table 2 here]

Identification of the cause and attitudes towards genitourinary symptoms

Although many women were not sure about the specific cause of their genitourinary symptoms, they often associated the onset or worsening of symptoms with their breast cancer treatment, particularly commencement of adjuvant endocrine therapy. One participant, who was told by her oncologist about the possibility of extending adjuvant endocrine therapy to ten years duration, suggested: "you take me off tamoxifen" [GT,Post,07] as the most helpful thing in dealing with her genitourinary problems. Another, who was experiencing urgency, incontinence and nocturia, was hopeful that: "as soon as I get off the Arimidex, these [symptoms] will stop. " [GA,Post,019]. Noticeably, the perceived association with cancer therapy was associated with high acceptance of the symptoms, i.e. symptoms 
were seen as something that women had "to get on with", so that "the cancer doesn't come back". In this context, women often minimised, accepted or disregarded altogether the physical and social restriction that resulted from genitourinary symptoms while weighing up the benefits of cancer therapy.

"Ifirst had a problem with my bladder when I had the cycle of Femara [...] it all happened around the time of my cancer treatment and it's still happening. [...] But I don't want to stop [...] the medicine my specialist wants me to have, unless it's really bad and he can change it, but they all are going to have problems so if that's the worst thing, you know, I have, 'cause it works for me." [GA,Pre,09]

“...the doctors put me on this [medication] for a good reason and I'm going to give it the best shot.[...] So if I have any symptoms with it or problems with it, I will put up with them in order to maintain the long-term effect that these drugs are going to give me." [GA,Post,018]

Ageing and menopause were mentioned as further reasons for changes in their genitourinary health with some participants specifically pinpointing the abrupt onset of "medically-induced early menopause" and "lack of oestrogen" as the underlying causes of their symptoms. Once again, these causal attributions were associated with high acceptance of genitourinary symptoms.

"I think it's got something to do with the 'mini' menopause [...] it just affects

everything. [...] I am in a medically-induced early menopause, it must have something to do with that 'old' thing." [GT,Pre,01]

"I think, with the lack of oestrogen, I was really sensitive to oestrogen and [...] I got cancer and I, then I went onto the treatment which blocks oestrogen [...] and, you know, it really has dried me up quite significantly, you know." [GT,Post,07]

Impact of symptoms on daily life

Women discussed the wide-ranging impact of genitourinary symptoms on their lives, particularly the profound ramifications symptoms had on their ability to engage in daily tasks and interactions. For instance, urinary urgency disrupted normal daily functioning, as it required frequent access to a bathroom. This in turn, discouraged normal social interactions leading to a lack of confidence in their ability to go out for long periods of time, or perform routine tasks such as shopping and exercising.

"I can't hold on to even get to a public toilet or a bathroom, it's horrible, sometimes I can be in a shop and I can just start to randomly leak. " [GA,Pre,09] “... a little bit to worry to going out and thinking 'oh, you know, am I going to find toilets in unfamiliar places? '” [GA,Post,014] 
Similarly, it impacted on women's confidence to work efficiently.

"It was horrible at work actually, I had one horrible boss and she saw me leaving the office too many times and so she was being like a bully and then I said 'well I have bladder problems, how can I come to work? '” [GA,Pre,09]

Nocturia leading to sleep disturbance had implications during the day as participants described being tired.

"Well it was waking me up every two hours to go to the toilet, I was exhausted."

[GA,Post,019]

Having these genitourinary problems caused feelings of anxiety, distress and worry. Additionally, respondents expressed their embarrassment of leaking in public or going to the toilet more often and in more of a rush than other people.

“Look, I don't like it. I've become really quite anxious, if I am not near a known bathroom. I feel embarrassed, especially if I do leak, yeah. And even when I go to sleep I just sometimes worry that I'm going to have an accident in bed, and I have had one or two." [GT,Pre,01]

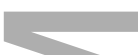

Impact of symptoms on sexual function

Only one woman complained of painful intercourse as limiting sexual activity, while two reported leakage occurring during intercourse. Women more often described decreased or lack of sexual intimacy being related to concerns with body image, or the breast cancer diagnosis and treatment itself, as opposed to genitourinary problems.

"Absolutely, for me, ever since the chemo, the cancer, no sexual intimacy at all."

[GA,Post,015]

"I couldn't stand to look at my body and [...] somehow all of these things come together and they make up for a situation where sex doesn't become important any longer. "[GA,Post,018]

Interestingly, some women who reported not being sexually active felt that genitourinary symptoms would not affect sexual function.

"No, I don't have a sexual relationship at the moment, I don't think it would affect

it." [GA,Post,014] 


\section{Help-seeking behaviour}

Motivations for seeking help

In total, nine women had discussed their current genitourinary concerns with their general practitioner (GP) $(\mathrm{GA}=5, \mathrm{GT}=4)$ who then referred them to a gynaecologist $(\mathrm{n}=3)$ and/or an urogynaecologist $(n=2)$. Only two participants who had seen the GP also saw their oncologist regarding genitourinary problems, one of whom was referred to a menopause clinic by her oncologist. Another woman mentioned that, besides her GP, she also saw a continence nurse advisor. These low rates of helpseeking behaviour reflected women's hesitancy to seek assistance, and were also expressed in the interviews.

Women's assessments about whether symptoms were important enough to act on seemed to be closely associated with participants' normative thinking, rapport with their healthcare professional and the perceived nature and duration of the presenting symptoms. An important motivating factor to seek help for genitourinary symptoms was the fear that such symptoms might be associated with a recurrence of cancer. For example, such concern prompted some women who were experiencing incontinence to see their GP for a referral.

"There is the possibility that this symptom could be related to cancer. First of all I would want to set aside any issue, you know, that there could be something worse." [GA,Post,014]

"...to get checked, make sure there was nothing else that might've been another cancer or something, 'cause I just want to make sure I don't have another cancer. "' [GA,Pre,09]

Participants also reported on the importance of the doctor-patient relationship, and that they found it easier to talk to a female doctor.

"Because she is a lady, and she is very nice doctor and loves me and explains to me everything and she has patience, she is not in a hurry you know, to see me." [GA,Post,011]

Obstacles to seeking help

Ten participants did not contact or see a healthcare professional about their genitourinary symptoms $(\mathrm{GA}=6, \mathrm{GT}=4)$. Reasons for not discussing their symptoms included the feeling that genitourinary concerns were of relatively little importance when compared with breast cancer concerns.

"Absolutely, not a big, not a big issue, it's nothing compared to the other things 
that I'm dealing with." [GA,Post,015]

The perception that symptoms were not sufficiently bothersome or "nothing sort of bad enough" to prompt a consultation was another important obstacle articulated as inhibiting help-seeking. Findings suggest that acknowledgement and acceptance of the presence of a problem were not always straightforward.

'I don't find that there is a symptom, the urgency, no it doesn't, because I don't soak myself." [GA,Post,017]

Additional obstacles were uncertainty about the causes and triggers, and in particular, the "lack of information" about available treatment options for genitourinary concerns. For instance, a number of respondents assumed that surgical procedures were the only available treatment to address genitourinary problems.

“... and are there, are there treatments? [...] What happens then? Is there a surgery? [...] I haven't done anything simply because as I said, I didn't have any information. It should be available." [GA,Post,017] “...having some urologist deciding that I need a bladder surgery or something?

Because like, I don't know if I would want to have any more surgeries, I mean, certainly not at the moment [...] and that's what I think would happen."

[GA,Post,018]

Another woman had the impression her genitourinary problems could not be solved because she would still be on endocrine therapy for breast cancer for a while.

"If I can do an operation, I don't want to do it because I'm still going to be taking the tablet [Femara]." [GA,Pre,09]

Some women were reluctant to seek help due to a desire to avoid further medical appointments based on previous negative experiences with the healthcare system or appointment overload from their breast cancer treatment and follow-up.

"I tell myself 'why are you going to the doctors?' I don't want to see any more doctors, you know, I am sick of the doctors. " [GA,Post,011] "It's waiting in hospitals, waiting to get help in some way, I think that's one of the reasons [.... I don't feel myself sitting in waiting rooms like, you know, because that's how the situation now is, just wait, and sit in waiting rooms for ages."

[GA,Post,013] 
Financial burden was also noted, with appointment fees and treatment expenses identified as strong motivators for delaying help-seeking.

“...you hardly ever find a gynaecologist who isn't going to charge you [...] plus

there's a lot of people that can't afford it [...] I've got no money these days. I put a lot of money for my reconstruction and it's really set me back a lot, you know."

[GA,Post,013]

"The cost and the issue around taking antibiotics and the cost of consultation and prescription potentially must be quite high if this is just a side effect of taking, of being on this medication." [GT,Post,06]

Moreover, differences in attitudes to disclosure about personal matters also prevented women from seeking advice.

"I guess it is very personal. Not easy for a lot of people to discuss." [GA,Post,015]

There was also evidence that genitourinary symptoms caused women embarrassment. When asked to identify the specific obstacles that potentially discouraged them from seeking treatment, comments such as: "Well I guess it's the embarrassing thing." [GT,Pre,03] were often mentioned. Indeed, many of the women revealed the desire to seek treatment in a confidential setting to ensure privacy and avoid potential embarrassment.

'Always confidential, I live with forty-five other women but I don't tell them, you know, no one knows that I have this problem." [GA,Post,016]

Help-seeking behaviour for sexual concerns

Most women had not mentioned any sexual issues to anyone, including their healthcare provider.

Only two claimed they would have or had openly discussed their sexual problems with their partners. Often, women were uncertain who to talk to regarding these sexual concerns as well as experiencing embarrassment about the topic. Nonetheless, a number of participants expressed a desire for support and/or treatment for sexual concerns.

"Nobody looks at the whole person they don't ask you how all of this impact in your sex life, and your self-esteem and everything else and I said inside I am dead'. [...] Really, I've got to say that there is a terrible hole out there in the postcancer treatment. [...] Nobody asks you these questions for a start. So if people don't even ask you or come anywhere close to the topic [...] I know that the majority of people probably even couldn't get to that point so they would never even dare to ask, they don't even ask, they don't seek, they just suffer in silence." 
[GA,Post,018]

\section{Treatment received and appraisal}

Women accessing treatment (including over-the-counter products and treatment offered by healthcare professionals) often described management as ineffective. Some reported doing pelvic floor exercises intermittently (mostly because of being forgetful), without any noticeable effect on their symptoms.

"They gave me the little machine to put inside to make your muscles work [...] but it didn't really work much, I mean, I forget to, I know there's exercises and I just forget about it, you know. " [GA,Post,010]

Others reported using either dietary supplements such as "cranberry juice" and probiotics, or medications including transdermal patches for overactive bladder, antibiotics and anticholinergic drugs. Similarly, most did not notice any improvements or they experienced bothersome side effects and eventually discontinued therapy.

"He started me on the patches and that wasn't doing anything and he started me on a tablet, yeah, I haven't taken them because I won't, well I took them for a while, but [...] the only thing they made me dry in the mouth and yeah, not where I wanted to be dry." [GA,Post,012]

Typically, women thought a meaningful treatment outcome would be a significant (70-100\%) improvement in their symptoms, but had more modest expectations of treatment in reality.

“Yes, I guess it's not going to be fair eighty percent. [...] That's too high, it's ambitious." [GT,Pre,03]

Overall, participants' expectations about treatment outcomes could be grouped into five key domains, which are represented in Table 3.

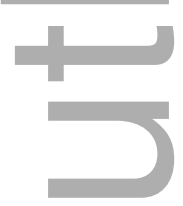

[Insert Table 3 here]

\section{Information needs and preferences}

Unmet needs

Mostly, women reported difficulties in accessing information about genitourinary symptoms as part of their breast cancer treatment. 
"Well maybe, a little bit of more information of what's going to happen, could happen, from the oncologist, you know. I've been just kind of discovering it myself, you know what I mean." [GT,Post,07]

They also reported that advice was often not actively offered by their healthcare providers. Instead, they indicated having sought information on genitourinary symptoms from multiple sources, including libraries, the internet, or by prompting for information during consultations.

"Well I only got it [information] because I went to the doctor." [GA,Post,09]

The credibility of information acquired through self-initiated efforts (e.g., searches on the internet) was pointed out as a concern. With women commenting that they would value information received from their treating doctor more.

'I just decided not to look anything more up because I don't know who's the author of a lot of these like, I prefer, I've got good doctors and I prefer [information from] them, like." [GA,Pre,09]

It was also apparent that when women actively sought assistance, clinicians were not always helpful. Some women described receiving limited information, clinicians being dismissive of their concerns and sometimes the lack of a physical examination or consistent monitoring of symptoms was voiced by participants. A woman who received prescription for antibiotics noted:

"He didn't examine me or anything, he took my word." [GA,Post,016]

Another participant who was experiencing dyspareunia stressed:

"I mentioned it ['I have unbelievable pain with penetration'] to one of my oncology associated people with my treatment [...] because that aspect of our lives was very important to the two of us and so I mentioned that and the answer was if intercourse is a problem there're other ways of pleasuring each other'. I think it was a very patronising comment and it wasn't really helping me at all in dealing with the most problem that I have." [GA,Post,018]

Essentially, the importance of communication about the potential side effects of cancer treatment, including genitourinary symptoms emerged as common themes in women's responses. In general, they wanted to be told about the possibility of genitourinary symptoms before going on the medication.

"I think the primary thing is to advise women or have a lot more information out there of what can be a side effect caused of being on [...] endocrine based therapy, it's very popular for women to be on that now for an extended length of time. But 
really, more information based on the women and more information for the GP.

[...] Often I think women who had breast cancer have very little opportunity to talk to people and a lot of the issues are very shaming so it is really important to offer them that chance." [GT,Post,06]

"I think it should be openly discussed by a treater, like the GP, or the, you know, the breast care nurse, or the oncologist, or breast surgeon [...] it should be told so we don't feel, 'hold on a second what's happening in here?'. It's just to be made aware of, and then maybe say 'look, ok it will all happen [...] expect this but maybe if you do this, it could help you'." [GT,Pre,01]

Finally, a checklist to prompt clinicians to discuss genitourinary and other symptoms during followup visits and encourage patients to report symptoms was suggested.

"I don't think I heard any [information regarding genitourinary symptoms], so,

yes, I guess [...] some sort of a checklist, well I think one should [...] probably

have a regular check-up so I think yes, it's good to have some questions ready isn't it? " [GA,Post,014]

Preferred source of information

Health professionals

In general, women considered information provided by either their GP or specialist by far the most important and valued source of information. This was related to a number of factors, including respect for healthcare providers' clinical expertise and good rapport.

"I think when I go and see my local GP [...] I've known this fella for many years so I can talk to him about anything." [GA,Post,013]

"Maybe the gynaecologist, 'cause it's in his area." [GT,Pre,03]

Written sources

Women also acknowledged that their health professionals might not be their only source of information; indicating a preference for also receiving printed information such as a brief leaflet or booklet provided with their medication or by the healthcare professional.

"Yes, it could just be a handout, for me it would be fine if he hand it out and say,

look you need to be aware of this, you got to take care of stuff like that."

[GT,Post,07]

"Of urination? They could've given some kind of brochure or something about it, 
when they send you to take the tablet, I think, I think just the pamphlets, and if you have anything you ask your doctor." [GT,Pre,03]

Nonetheless, there were suggestions that written sources may not reach all women.

"I think that not many people take time to read fact sheets and things like that, I'm talking really about people in my age group, my generation group, the baby boomers' age group, you know, I mean, I don't think they should go bother reading fact sheets and things like that." [GA,Post,013]

Some women felt that web-based resources provided greater accessibility and would enable them to gain a better understanding of their symptoms; but then again, they also discussed concerns about the accuracy of health information acquired via the internet.

"I think a lot of people would like an online resource to use." [GT,Pre,01]

“...but sometimes you don't know the right website to go to." [GA,Post,014]

Group talks

While there was an indication that some women "didn't mind" group talks as a means to gather information on genitourinary concerns, others mentioned that this would not be of real value to them. Particularly, for those with previous experience of breast cancer support groups.

"One of the problems with talks is that a lot of people think they will go, think about going but they don't end up going [...] so it's not as successful as a mean to reaching people really is it?" [GA,Post,014]

Publicity in mainstream media

Some participants recognised that publicity in the media increased awareness about symptoms; however, women felt it did not prompt them to ask for medical support. On the contrary, participants believed that media publicity may strengthen breast cancer patients' beliefs that genitourinary disorders are a widespread problem among older/menopausal women, and hence women may feel it would not be appropriate to seek medical support.

"I must admit since the ad has been on the television, you know, it's a, like bladder leakage, I really do think that that has... well personally has made a difference. Because I think that's one of the reasons why I haven't sought treatment as well. Because I seem to think well, it is a common problem amongst women perhaps getting to a certain age so, yes. " [GT,Pre,05] 
Preferred amount of information and timing of its delivery

Although most women wanted "as much [information] as possible", there was some variation in terms of the amount of information desired and the timing of its delivery, as illustrated below.

"So when you get cancer you know, you just start to wonder and probably after a year or something, then it would be a good time to someone to talk to you about 'oh this could happen, or this could happen', or something [...] because you don't take much, you just think, 'am I going to live?' you know, or 'am I going to die?' you know. And you have to deal with all the emotion of people and everything, you just [...] but after a year everything is kind of back underneath normal hopefully." [GT,Post,07]

"I would like a one a very simple, very relatively small information piece to advise people, you know, what the symptoms may be or may not be, sometimes they develop as a result of being on aromatase inhibitors $[\ldots]$ and then more of what you should do about it." [GT,Post,06]

\section{DISCUSSION}

To the best of our knowledge, this is the first study to qualitatively explore the understanding of genitourinary symptoms and associated impact on daily life and sexual functioning in women with early breast cancer receiving adjuvant endocrine therapy. Although there were similarities between the experiences described by women with breast cancer in this study and those of healthy women reported in the literature, we also observed distinct attitudes and specific concerns that appear to be unique to women with early breast cancer taking adjuvant endocrine therapy.

Our findings support existing evidence that shows that in general, genitourinary symptoms do impact on personal, social and physical activities (George and Davenport, 2012), are often attributed to anxiety and stress (Coyne et al, 2009), are a source of embarrassment (Goldstein et al, 2013), and impair daily activities (Papanicolaou et al, 2005). It was also apparent that women with breast cancer minimised genitourinary symptoms and perceived that their symptoms were a 'normal' part of aging or menopause (Shaw et al, 2008; Shaw et al, 2001; Bush et al, 2001). As a consequence, women seemed unlikely to raise genitourinary symptoms in medical consultations. Our data indicates that the onus of the discussion sits with the healthcare professionals. However, even healthcare professionals seemed casual in their approach to the importance of these symptoms based on the patient reports. Most women appeared resigned to "put up with" symptoms, because others, including their clinicians, seemed to accept them as 'normal' (Fu et al, 2008; Cowley et al, 2000). Our data suggest that there is an unmet need for acceptance and recognition of the importance of genitourinary 
symptoms by healthcare professionals and that they should facilitate discussion of symptoms, rather than accepting them as the norm.

This study also highlights the relatively little attention the women in this study give to genitourinary concerns (even if negatively impacting on everyday life) compared to their fears and concerns about breast cancer recurrence. The potential benefit of adjuvant endocrine therapy and their desire to continue on the prescribed treatment were the main reasons for accepting and tolerating symptoms. This finding is consistent with the findings of other studies regarding the attitudes of women with breast cancer and tolerance of other treatment-related side effects (e.g. fatigue, cognitive disturbance, pain) (Binkley et al, 2012; Rosendale and Fu, 2010).

A key finding was the limited access to information related to genitourinary symptoms/side effects that was available to women and the low level of help-seeking behaviour. Many women in this study felt that their treating clinicians had not fully informed them about the potential impact of adjuvant endocrine therapy on their genitourinary tract, consistent with previous research (Lester and Bernhard, 2009). These results suggest that there is a gap in the provision of information about genitourinary symptoms after breast cancer. Some researchers have identified that a lack of knowledge or awareness of treatment options may affect help-seeking for genitourinary concerns (Shaw et al, 2001), which was supported by our findings. Additionally, participants believed that the availability of information materials that address the potential adverse effects of therapy and potential treatment options should be improved.

Most women preferred brief and focused paper-based resources alongside information obtained directly from healthcare professionals. Similar to other studies, some women appeared less confident about actively searching for information (Perera et al, 2014) and regarded information received from GPs or specialists to be a more reliable and more acceptable form of communication. This provides further support for clinicians to ask about genitourinary symptoms and offer information and advice about potential treatments. Educating clinicians about the factors associated with help-seeking as well as the available management options may improve QoL for patients and potentially increase compliance with endocrine therapy. More research is needed on the role of symptom checklists and/or patient prompt sheets in facilitating communication about genitourinary symptoms as well as other adverse effects of treatment.

The responses provided by participants in this study did not differ according to sociodemographic or clinical characteristics, including menopausal status, age, marital status or education. However, given the qualitative nature of the research, and the small number of participants, it is not possible to conclude that there is no difference between the needs of different groups. In other studies, age has 
been associated with information needs priorities (Janz et al, 2008; Tariman et al, 2014). For instance, it has been reported that younger women with breast cancer are more likely to prioritise sexual issues and attractiveness while older women prioritise information related to healthcare (Tariman et al, 2014). In our study, the only comment suggesting that there might be differences according to age groups was in regards to written materials potentially not reaching older women who may prefer information provided directly by their healthcare professional. While this was one viewpoint, it would be interesting to explore this issue further as it was beyond the scope of this study.

\section{STUDY STRENGHTS AND LIMITATIONS}

By not using genitourinary symptoms as a criterion for eligibility, this study was able to identify a gap in patient-clinician communication of these symptoms, as most women in the study were experiencing symptoms but had not discussed it with clinicians. In keeping with the principles of qualitative research, this study aimed for maximum variation and not numerical representation. Women taking both TAM and AI, range of ages, parity, education, marital and menopause status were represented in this study. However, given all women were treated at a metropolitan large tertiary hospital, the findings may not be transferable to the general breast cancer population. The findings of this study may also have been strengthened by the use of data triangulation methods, such as medical record review or patient journals. It is possible that the use of both telephone and face-to-face interviews may have influenced the findings, given each modality has its own strengths and limitations. However, no differences were observed in participant responses according to the interview delivery method. Larger quantitative studies could explore and verify the informational needs and preferences of these women, determine the factors influencing women's help-seeking behaviour, as well as identify associations between daily life impairment and seeking further treatment. In addition, further studies should be conducted to identify which women are most likely to experience significant genitourinary symptoms, whether they are associated with other adverse effects of adjuvant endocrine therapy (e.g., joint pain, hot flashes, etc.) and whether they compromise compliance and early cessation of therapy. Furthermore, there are increasing numbers of premenopausal women being recommended adjuvant ovarian suppression and AIs for at least five years and it is unclear what the impact will be on genitourinary symptoms in these younger women and this should also be studied. While this study aimed to explore the experiences of women on endocrine therapy, there are many health professionals involved in the care of breast cancer patients including medical oncologists, GPs, breast care nurses, etc. Future studies exploring the perspective of these healthcare professionals are needed to validate these findings and help to identify the barriers to improve communication between patients and their caregivers. 


\section{CONCLUSION}

Genitourinary symptoms are common in women with early breast cancer on adjuvant endocrine therapy. Many women are reluctant to mention these symptoms or to seek help and clinicians should specifically ask about genitourinary symptoms, as well as other side effects, and offer information and advice regarding their management. Prior to commencing adjuvant endocrine therapy all women should be informed about the potential adverse effects of treatment on the genitourinary tract and the interventions or treatment options available if problems arise. Women should also be encouraged to seek help if they experience adverse effects. More research is needed to better understand the barriers to discussion of genitourinary symptoms for both patients and clinicians given the reticence for these issues to be raised during consultations.

\section{ACKNOWLEDGMENTS}

Many people have been integral to the success of this study and we would like to acknowledge their support. We are most grateful for the valuable contribution of all women who participated in the interviews, as well as the Breast Cancer Network Australia (BCNA) Consumer Representative, Ms Yvonne Shaw and Prof Bettina Meiser for their meaningful advice and input in this project. Dr Peate is supported by an Early Career Fellowship from the National Breast Cancer Foundation (ECF-15005) and Prof. Hickey is supported by a NHMRC Practitioner Fellowship Award (ID 1058935).

\section{REFERENCES}

American Joint Committee on Cancer (2010) Cancer Staging Manual. in: Edge, S., Byrd, D. and Compton, C. (eds) Breast Cancer Staging. 7th ed. Springer-Verlag: New York.

Australian Institute of Health and Welfare (2014) Cancer in Australia: an overview, 2014. Cancer series no. 78. Cat. no. CAN 75. AIHW: Camberra.

Baumgart, J., Nilsson, K., Evers, A., Kallak, T. and Poromaa, I. (2013) Sexual dysfunction in women on adjuvant endocrine therapy after breast cancer. Menopause, 20: 162-168.

Baumgart, J., Nilsson, K., Stavreus-Evers, A., Kask, K., Villman, K., Lindman, H., Kallak, T. and Sundström-Poromaa, I.A. (2011) Urogenital disorders in women with adjuvant endocrine therapy after early breast cancer. American Journal of Obstetrics and Gynecology, 204: e1-7.

Binkley, J.M., Harris, S.R., Levangie, P.K., Pearl, M., Guglielmino, J., Kraus, V. and Rowden, D. (2012) Patient perspectives on breast cancer treatment side effects and the prospective surveillance model for physical rehabilitation for women with breast cancer. Cancer, 18: 2207-2216.

Bush, T.A., Castellucci, D.T. and Phillips, C. (2001) Exploring women's beliefs regarding urinary incontinence. Urologic Nursing, 21: 211-218. 
Buzdar, A., Howell, A., Cuzick, J., Wale, C., Distler, W., Hoctin-Boes, G., Houghton, J., Locker, G.Y. and Nabholtz, J.M. (2006) Comprehensive side-effect profile of anastrozole and tamoxifen as adjuvant treatment for early-stage breast cancer: long-term safety analysis of the ATAC trial. Lancet Oncol, 7: 633-43.

Cella, D., Fallowfield, L., Barker, P., Cuzick, J., Locker, G. and Howell, A. (2006) Quality of life of postmenopausal women in the ATAC ("Arimidex", tamoxifen, alone or in combination) trial after completion of 5 years' adjuvant treatment for early breast cancer. Breast Cancer Res Treat, 100: 273-84.

Chin, S.N., Trinkaus, M., Simmons, C., Flynn, C., Dranitsaris, G., Bolivar, R. and Clemons, M. (2009) Prevalence and severity of urogenital symptoms in postmenopausal women receiving endocrine therapy for breast cancer. Clinical Breast Cancer, 9: 108-117.

Cowley, L., Heyman, B., Stanton, M. and Milner, S.J. (2000) How women receiving adjuvant chemotherapy for breast cancer cope with their treatment: a risk management perspective. Journal of Advanced Nursing, 31: 314-321.

Coyne, K.S., Wein, A.J., Tubaro, A., Sexton, C.C., Thompson, C.L., Kopp, Z.S. and Aiyer, L.P. (2009) The burden of lower urinary tract symptoms: evaluating the effect of LUTS on healthrelated quality of life, anxiety and depression: EpiLUTS. BJU International, 103: 4-11.

Donovan, K.A., Boyington, A.R., Ismail-Khan, R. and Wyman, J.F. (2012) Urinary Symptoms in Breast Cancer: A Systematic Review. Cancer, 118: 582-593.

Fallowfield, L.J., Bliss, J.M., Porter, L.S., Price, M.H., Snowdon, C.F., Jones, S.E., Coombes, R.C. and Hall, E. (2006) Quality of life in the intergroup exemestane study: a randomized trial of exemestane versus continued tamoxifen after 2 to 3 years of tamoxifen in postmenopausal women with primary breast cancer. J Clin Oncol, 24: 910-7.

Fu, M.R., Liu, B. and Haber, J. (2008) 'Making the best of it': Chinese women's experiences of adjusting to breast cancer diagnosis and treatment. Journal of Advanced Nursing, 63: 155165 .

George, A. and Davenport, T.C. (2012) Management of Urinary Incontinence. Pharmacy and Therapeutics, 37: 345-361, 361B-361H.

Goldstein, I., Dicks, B., Kim, N.N. and Hartzell, R. (2013) Multidisciplinary overview of vaginal atrophy and associated genitourinary symptoms in postmenopausal women. Sexual Medicine, 1: 44-53.

Gupta, P., Sturdee, D.W., Palin, S.L., Majumder, K., Fear, R., Marshall, T. and Patterson, I. (2006) Menopausal symptoms in women treated for breast cancer: the prevalence and severity of symptoms and their perceived effects on quality of life. Climacteric : the Journal of the International Menopause Society, 9: 49-58.

Howell, A., Cuzick, J., Baum, M., Buzdar, A., Dowsett, M., Forbes, J.F., Hoctin-Boes, G., Houghton, J., Locker, G.Y. and Tobias, J.S. (2005) Results of the ATAC (Arimidex, Tamoxifen, Alone 
or in Combination) trial after completion of 5 years' adjuvant treatment for breast cancer.

Lancet, 365: 60-2.

Janz, N.K., Mujahid, M.S., Hawley, S.T., Griggs, J.J., Hamilton, A.S. and Katz, S.J. (2008)

Racial/ethnic differences in adequacy of information and support for women with breast

cancer. Cancer, 113: 1058-67.

Lester, J.L. and Bernhard, L.A. (2009) Urogenital atrophy in breast cancer survivors. Oncology

Nursing Forum, 36: 693-698.

Lester, J.L., Bernhard, L.A. and Ryan-wenger, N. (2012) A Self-Report Instrument That Describes

Urogenital Atrophy Symptoms in Breast Cancer Survivors. Western Journal of Nursing

Research, 34: 72-96.

Marshall, M.N. (1996) Sampling for qualitative research. Family Practice, 13: 522-526.

Miles, M.B. and Huberman, A.M. (2002) Reflections and Advice. Sage Publications, Thousand Oaks,

CA.

Morales, L., Neven, P., Timmerman, D., Christiaens, M.R., Vergote, I., Van Limbergen, E.,

Carbonez, A., Van Huffel, S., Ameye, L. and Paridaens, R. (2004) Acute effects of tamoxifen and third-generation aromatase inhibitors on menopausal symptoms of breast cancer patients. Anticancer Drugs, 15: 753-60.

Morse, J.M. (1995) The Significance of Saturation. Qualitative Health Research, 5: 147-149.

Murphy, C.C., Bartholomew, L.K., Carpentier, M.Y., Bluethmann, S.M. and Vernon, S.W. (2012)

Adherence to adjuvant hormonal therapy among breast cancer survivors in clinical practice: a systematic review. Breast Cancer Research and Treatment, 134: 459-478.

Niravath, P., Rimawi, M.F. and Osborne, C.K. (2014) Aromatase Inhibitor Adverse Effects: Are We Sweeping Them Under theRug? . Journal of Clinical Oncology, 32: 3779.

Papanicolaou, S., Hunskaar, S., Lose, G. and Sykes, D. (2005) Assessment of bothersomeness and impact on quality of life of urinary incontinence in women in France, Germany, Spain and the UK. BJU International, 96: 831-838.

Partridge, A.H., LaFountain, A., Mayer, E., Taylor, B.S., Winer, E. and Asnis-Alibozek, A. (2008) No Adherence to Initial Adjuvant Anastrozole Therapy Among Women With Early-Stage Breast Cancer. Journal of Clinical Oncology, 26: 556-562.

Perera, J., Kirthinanda, D.S., Wijeratne, S. and Wickramarachchi, T.K. (2014) Descriptive cross sectional study on prevalence, perceptions, predisposing factors and health seeking behaviour of women with stress urinary incontinence. BMC Women's Health, 14: 78.

Portman, D.J. and Gass, M.L. (2014) Genitourinary syndrome of menopause: new terminology for vulvovaginal atrophy from the International Society for the Study of Women's Sexual Health and the North American Menopause Society. Menopause, 21: 1063-1068. 
Rosendale, M. and Fu, M.R. (2010) Confronting the unexpected: temporal, situational, and attributive dimensions of distressing symptom experience for breast cancer survivors. Oncology Nursing Forum, 37: E28-33.

Schiavon, G. and Smith, I.E. (2014) Status of adjuvant endocrine therapy for breast cancer. Breast Cancer Research, 16: 206.

Shaw, C., Brittain, K., Tansey, R. and Williams, K. (2008) How people decide to seek health care: a qualitative study. International Journal of Nursing Studies, 45: 1516-1524.

Shaw, C., Tansey, R., Jackson, C., Hyde, C. and Allan, R. (2001) Barriers to help seeking in people with urinary symptoms. Family Practice, 18: 48-52.

Sheri, A. and Dowsett, M. (2012) Developments in Ki67 and other biomarkers for treatment decision making in breast cancer. Annals of Oncology, 23: x219-227.

Sousa, M.S., Peate, M., Jarvis, S., Hickey, M. and Friedlander, M. (2017) A clinical guide to the management of genitourinary symptoms in breast cancer survivors on endocrine therapy. Ther Adv Med Oncol, 9: 269-285.

Tariman, J.D., Doorenbos, A., Schepp, K.G., Singhal, S. and Berry, D.L. (2014) Information Needs Priorities in Patients Diagnosed With Cancer: A Systematic Review. J Adv Pract Oncol, 2014: 115-122.

Thurlimann, B., Keshaviah, A., Coates, A.S., Mouridsen, H., Mauriac, L., Forbes, J.F., Paridaens, R., Castiglione-Gertsch, M., Gelber, R.D., Rabaglio, M., Smith, I., Wardley, A., Price, K.N. and Goldhirsch, A. (2005) A comparison of letrozole and tamoxifen in postmenopausal women with early breast cancer. N Engl J Med, 353: 2747-57.

Trinkaus, M., Chin, S., Wolfman, W., Simmons, C. and Clemons, M. (2008) Should urogenital atrophy in breast cancer survivors be treated with topical estrogens? . Oncologist, 13: 222231 .

Zibecchi, L., Greendale, G.A. and Ganz, P.A. (2003) Continuing education: Comprehensive menopausal assessment: an approach to managing vasomotor and urogenital symptoms in breast cancer survivors. Oncology Nursing Forum, 30: 393-407.

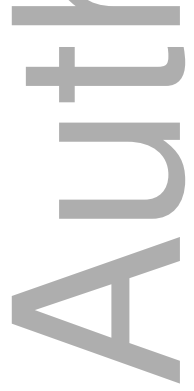


Table1. Sociodemographic and clinical characteristics of sample $(\mathrm{N}=32)$

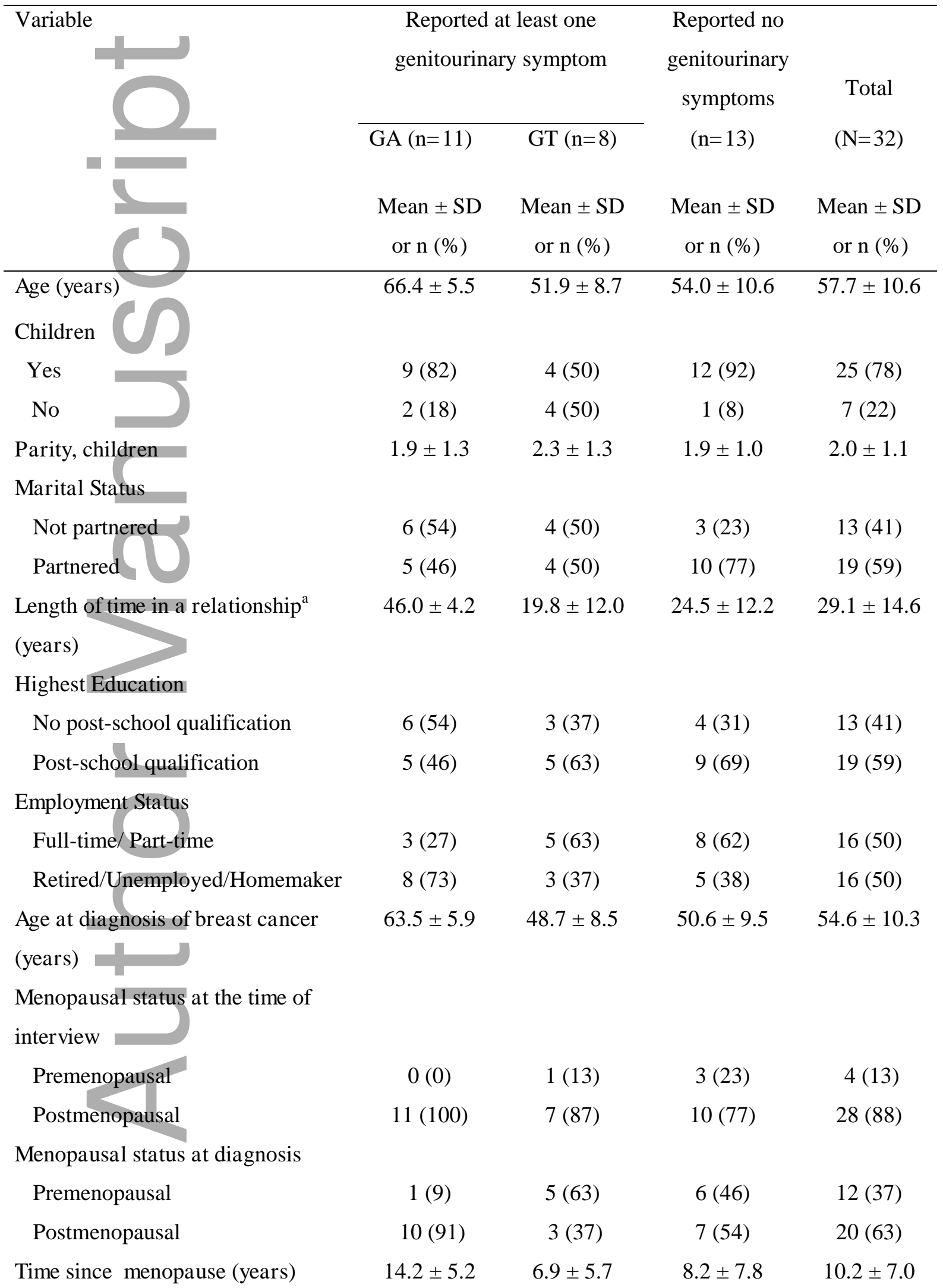


Duration of endocrine therapy use (months)

\section{Additional treatment}

\begin{tabular}{lcccc} 
Chemotherapy & $9(82)$ & $7(87)$ & $11(85)$ & $27(84)$ \\
Radiation therapy & $9(82)$ & $6(75)$ & $11(85)$ & $26(81)$ \\
Goserelin & $0(0)$ & $1(13)$ & $1(8)$ & $2(6)$ \\
Oophorectomy & $0(0)$ & $0(0)$ & $1(8)$ & $1(3)$ \\
\hline
\end{tabular}

${ }^{\mathrm{a}}$ If married or partnered

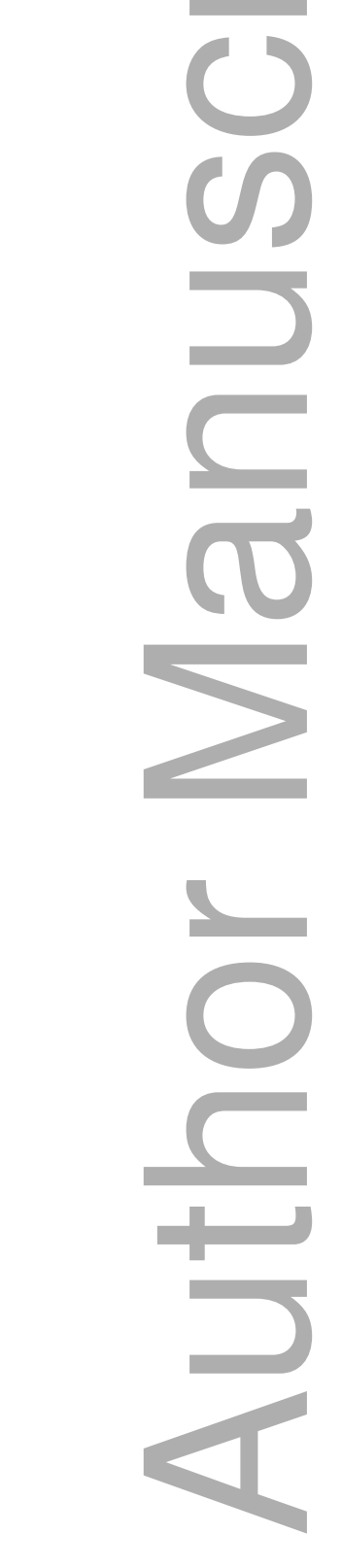

$26.6 \pm 23.1 \quad 24.0 \pm 19.1$

$27.8 \pm 19.1$

$26.5 \pm 19.9$

This article is protected by copyright. All rights reserved 
Table 2. Summary of participants' reported genitourinary problems

Quotation
"I go very often to the toilet." [GA,Post,011]
"I do tend to go to the bathroom quite often." [GT,Pre,05]
"I would say almost like every half hour I might feel the need that I have to
go to the bathroom." [GT,Pre,02]
"...it's a bit urgent for me." [GA,Post,013]
"I "Whe get a bit of urgency." [GA,Post,015]
[GA,Post,019] want to go [to the toilet], I want to go all of a sudden."
"I seriously have to go to the toilet. The minute that I feel that I have to go
to the toilet, I can't hold it [...] I need the toilet." [GT,Pre,04]

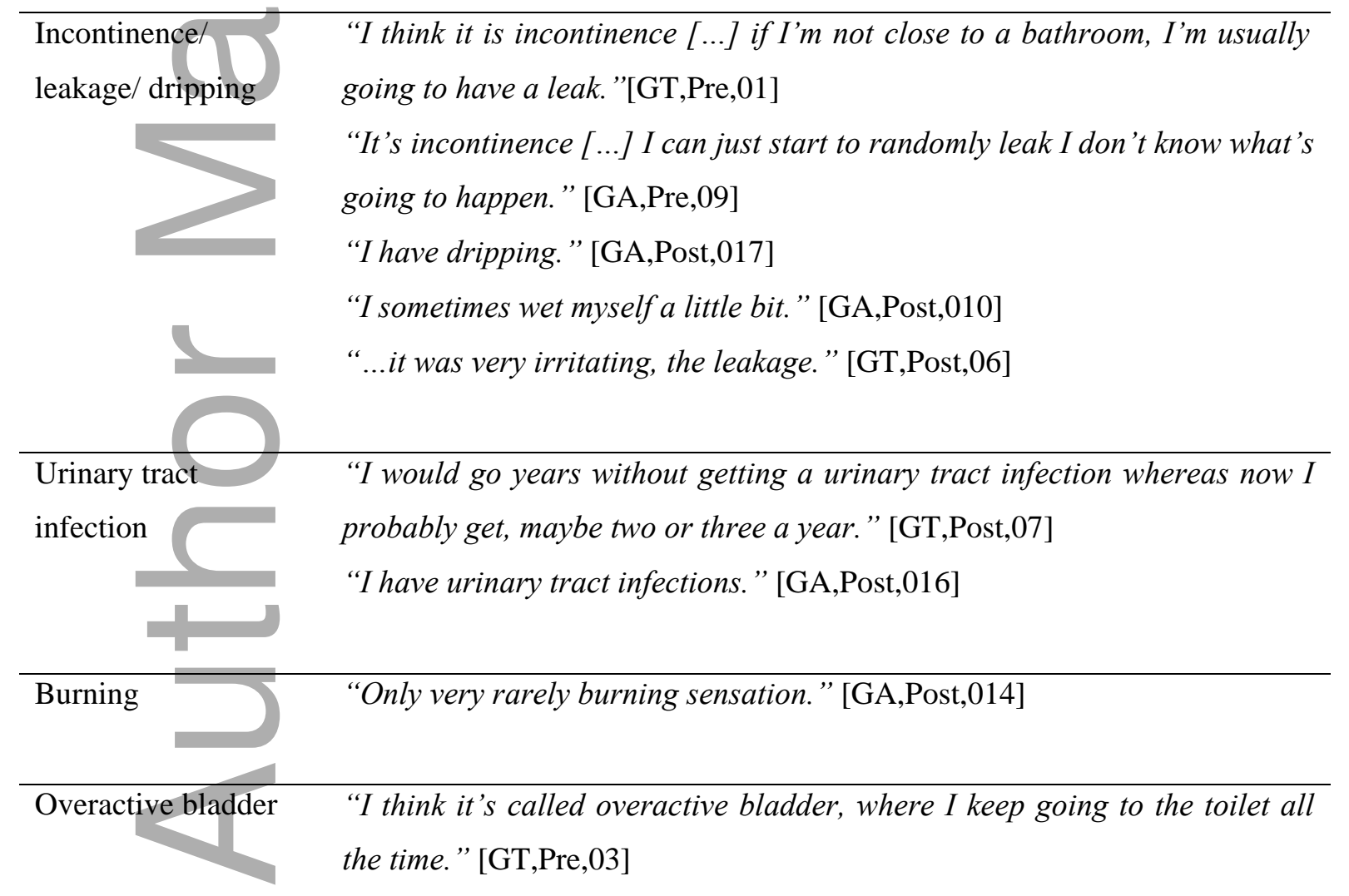

Discomfort/ soreness "I thought I was very sore [...] as soon as I started taking tamoxifen, the first week, it was sore ['down there'], it was uncomfortable.” [GT,Post,08]

This article is protected by copyright. All rights reserved 


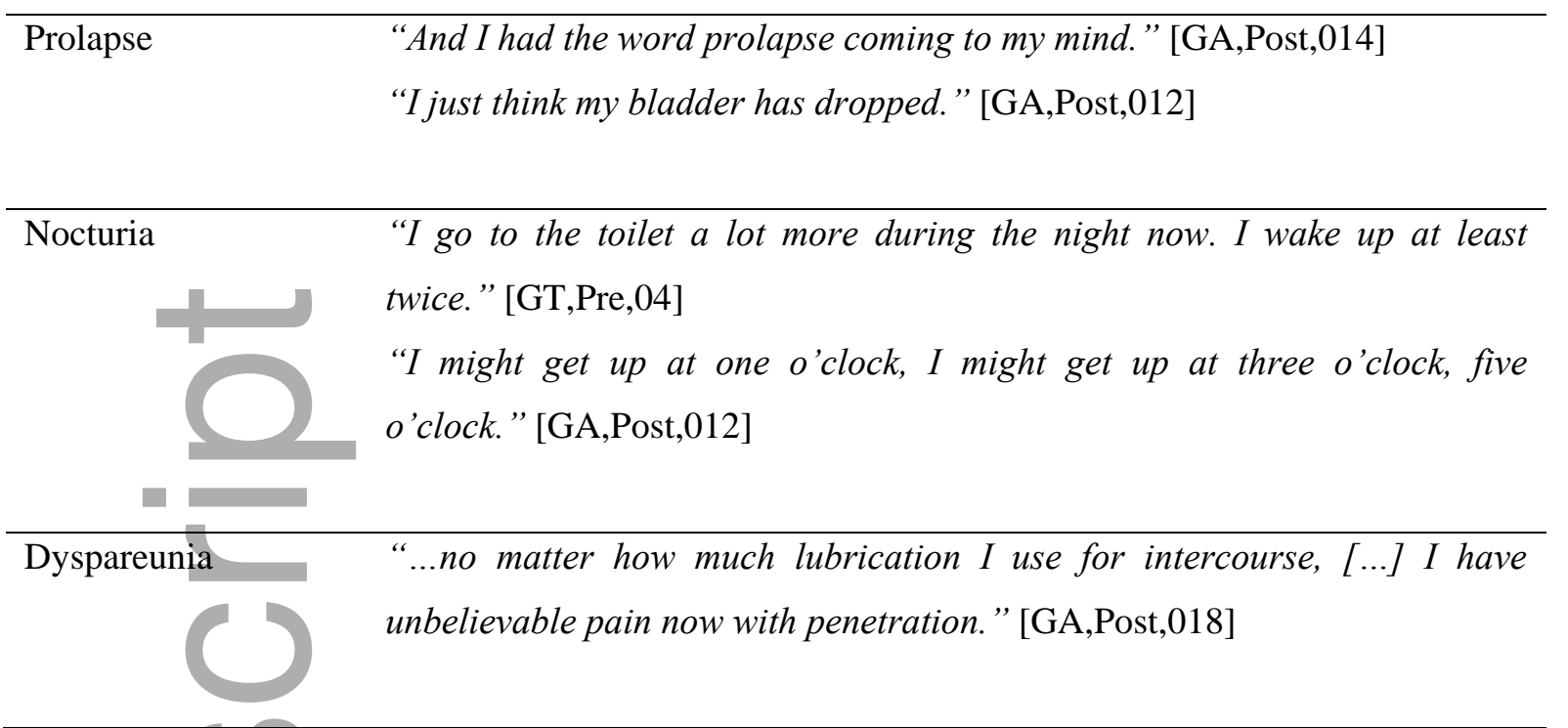

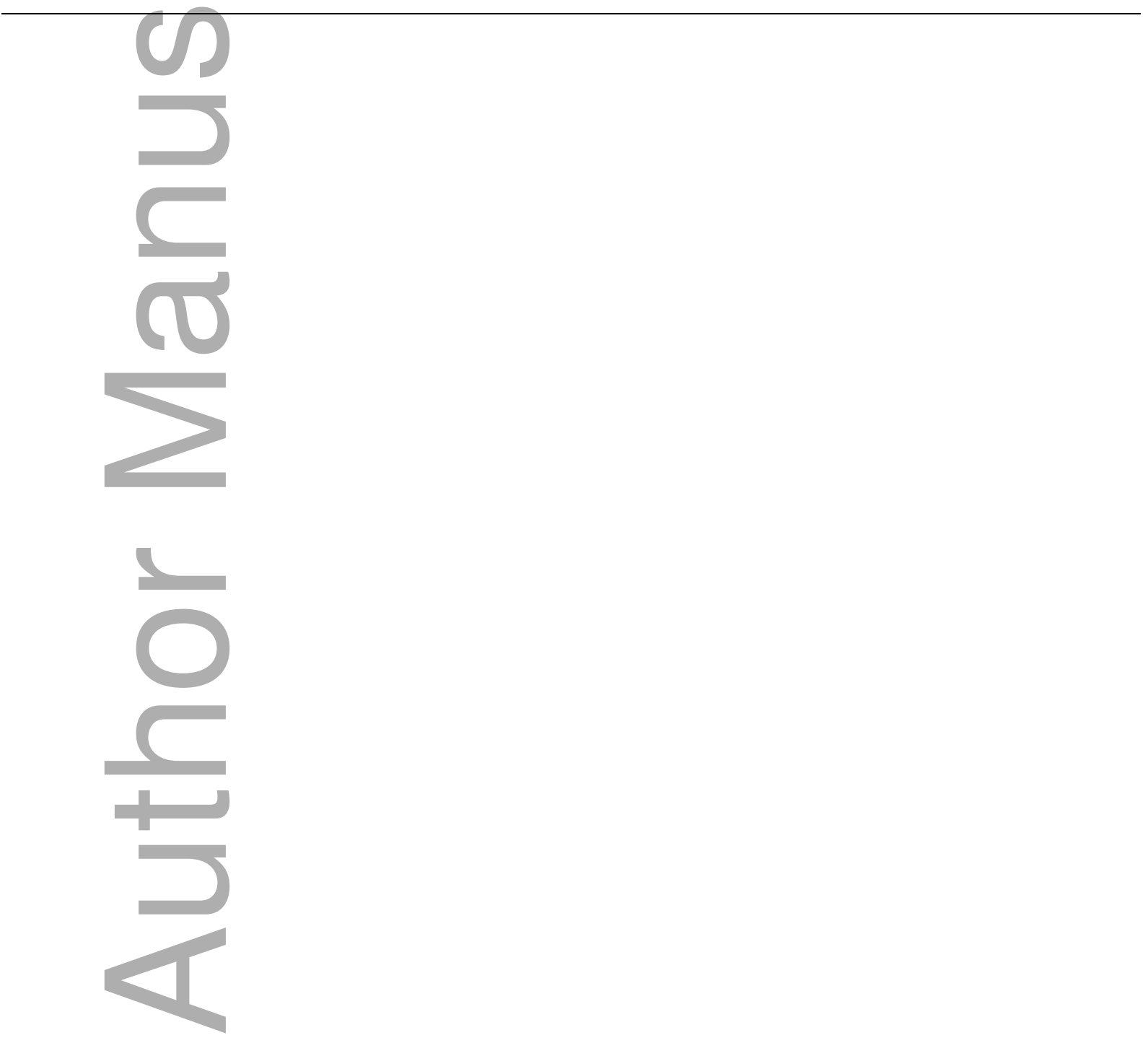


Table 3. Summary of participants' treatment expectations regarding genitourinary symptoms

\begin{tabular}{|c|c|}
\hline $\begin{array}{l}\text { Key domains of expectations of } \\
\text { treatment outcome }\end{array}$ & Quotation \\
\hline $\begin{array}{l}\text { 'I don't care, as long as it is not something } \\
\text { serious like cancer' }\end{array}$ & $\begin{array}{l}\text { “....as long as I knew I didn't have cancer I } \\
\text { wouldn't, I wouldn't care.” [GA,Pre,09] }\end{array}$ \\
\hline 'I don't think I can be helped at all' & $\begin{array}{l}\text { "I don't know if anything is going to help me that's } \\
\text { all." [GA,Post,010] }\end{array}$ \\
\hline 'To be com & $\begin{array}{l}\text { "Yeah, so I only want that fixed up [...] yes, } \\
\text { cured." [GA,Post,012] } \\
\text { "Yeah, I just hope it to go away [...] Cured, yes, } \\
\text { yes." [GT,Post,07] }\end{array}$ \\
\hline $\begin{array}{l}\text { 'To prevent new symptoms or worsening } \\
\text { of the ones already experienced' }\end{array}$ & $\begin{array}{l}\text { "I guess that they don't get any worse." } \\
\text { [GA,Post,015] } \\
\text { "To prevent new symptoms [...] that would be } \\
\text { good." [GA,Post,016] }\end{array}$ \\
\hline $\begin{array}{l}\text { 'To improve symptoms and/or functioning } \\
\text { (including symptom relief and } \\
\text { enhancement of ability to engage in } \\
\text { routine activities and well-being)' }\end{array}$ & $\begin{array}{l}\text { “...to relieve my symptoms would be possible [...] } \\
\text { improve whatever is wrong with me." } \\
\text { [GA,Post,013] } \\
\text { "That I wouldn't need to, no longer need to wear a } \\
\text { pad, yeah. A bit more confidence in going for walks } \\
\text { and exercising without having to worry, yes." } \\
\text { [GT,Pre,05] } \\
\text { "I would love it if I don't leak and I would love it if } \\
\text { I don't, if I can hold myself." [GT,Pre,01] } \\
\text { "I guess not to have the urge so much to go, and } \\
\text { hopefully when I go only a little bit comes out and } \\
\text { it's not like a lot, I would like to be more normal, or } \\
\text { on the normal range sort of thing." [GT,Pre,03] }\end{array}$ \\
\hline
\end{tabular}




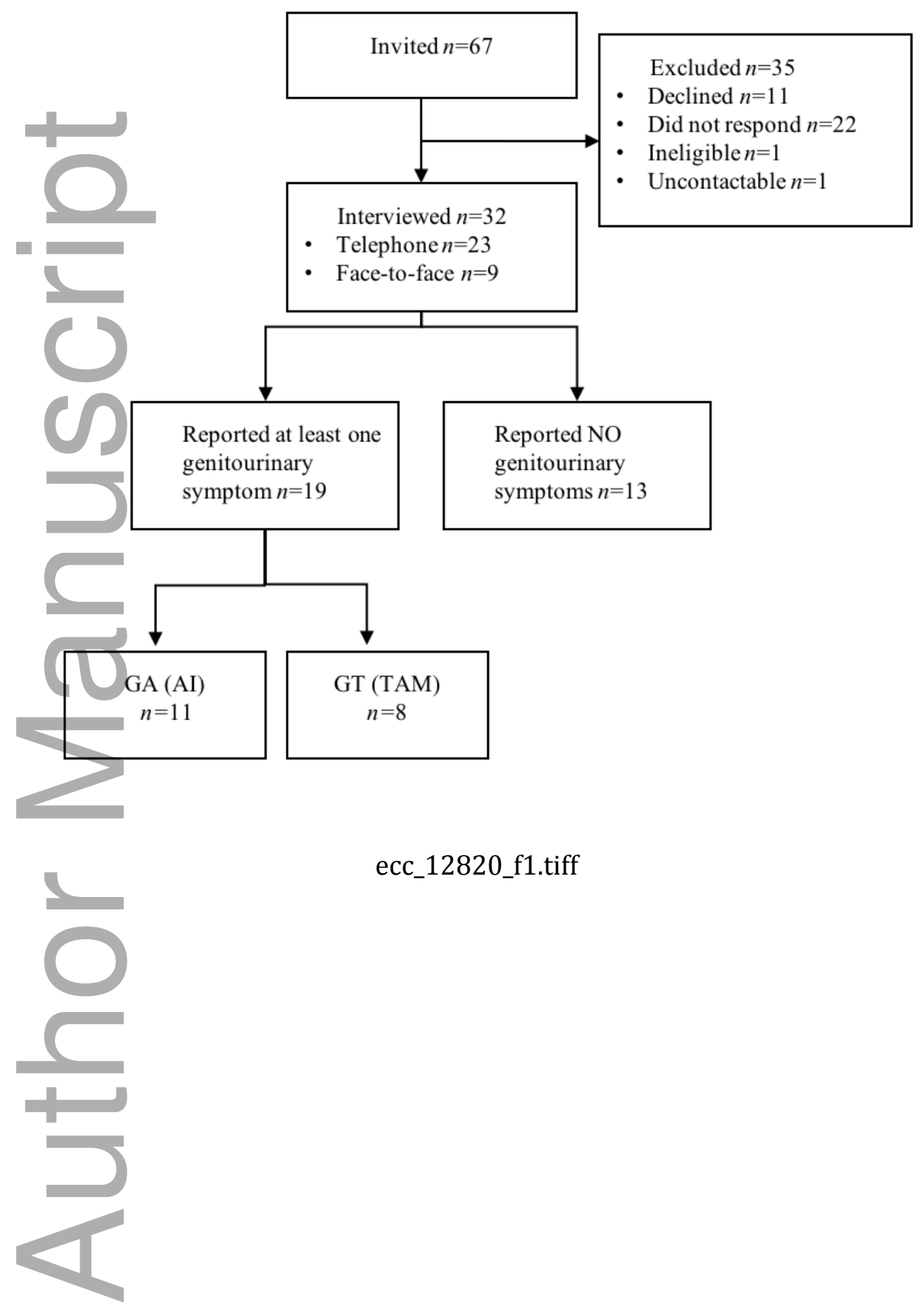




\section{University Library}

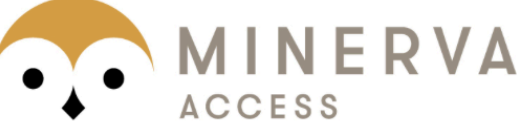

A gateway to Melbourne's research publications

Minerva Access is the Institutional Repository of The University of Melbourne

Author/s:

Sousa, M;Peate, M;Lewis, C;Jarvis, S;Willis, A;Hickey, M;Friedlander, M

Title:

Exploring knowledge, attitudes and experience of genitourinary symptoms in women with early breast cancer on adjuvant endocrine therapy

Date:

2018-03-01

Citation:

Sousa, M., Peate, M., Lewis, C., Jarvis, S., Willis, A., Hickey, M. \& Friedlander, M. (2018). Exploring knowledge, attitudes and experience of genitourinary symptoms in women with early breast cancer on adjuvant endocrine therapy. EUROPEAN JOURNAL OF CANCER CARE, 27 (2), https://doi.org/10.1111/ecc.12820.

Persistent Link:

http://hdl.handle.net/11343/283512 